\title{
MEANING AND PROCESS AS DISTINGUISHED BY THE REACTION METHOD
}

\author{
By H. P. WELD, Cornell University
}

II. Experimental:

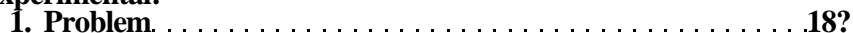

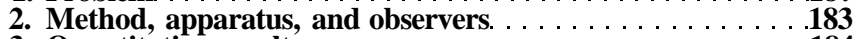

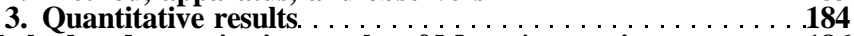

III. Method and quantitative results of Moore's experiment . . . . . 186

IV. The attitudes set up in our observers by the two instructions.. 188

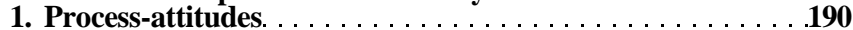

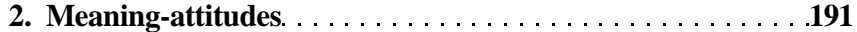

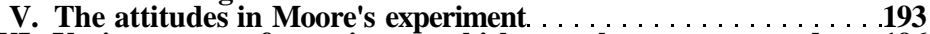

VI. Various types of meaning to which our observers reacted... 196

VII. The types of meaning to which Moore's observers reacted.. 201

VIII. The temporal relation of different types of meaning. . . . . . .203

IX. The temporal relation of meaning and correlated process. . . . 205

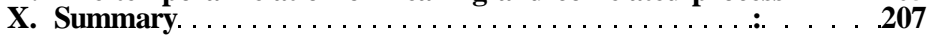

\section{Introduction}

We are concerned, in this paper, with certain aspects of the relation of logic to psychology, of meaning to contentprocess. The psychological point of orientation is to be found in the context-theory of meaning. ${ }^{1}$ This theory is one of those general formulations, well known to science, which derive from a comprehensive survey of facts, and which look to experiment for verification of their schema and completion of their detail. It is of the essence of the theory that meaning, like everything else, may be regarded from different points of view; meaning is biological when regarded as the organism's reaction upon a situation, $i$. $e$., upon a complex of stimuli to which it has become adapted; meaning is logical ${ }^{2}$ when regarded as significance, as interpretation, as knowl-

${ }^{1}$ For general statements of the theory, see E. B. Titchener, Experimental Psychology of the Thought-Processes, 1909, pp. I74ff.; TextBook of Psychology, 1910, pp. 36>ff; Beginner's Psychology, 1915, pp. 26S, n8ff. We hope later to publish a detailed statement of the theory and an account of its precursors in the history of psychology.

${ }^{2}$ We use the term 'logical' in its broad sense. The meanings with which we are particularly concerned are not those of systematic logic; they are rather individual or pre-logical meanings. 
edge; it is psychological when regarded as an item of mental experience, a group of content-processes. Meaning, then, is biological response, or logical signification, or psychological experience, as the case may be. Psychologically considered it is in the first instance, according to the context-theory, the complex of processes accruing to the given process through the situation in which the organism finds itself. Like all, such formations, this complex is subject to the law of mental growth and decay; content-processes which at first are vivid and complete gradually become obscure and fragmentary, and ultimately may drop out of consciousness altogether. Thenceforth, in explanatory psychology, logical meaning is correlated with brain-habit. The problem which the context-theory of meaning sets for psychology, therefore, is in general twofold: descriptive, for the observable content-process coordinate with the logical meaning must be described; and genetic, for content-processes which are no longer observable must be rediscovered. The experimental part-problems are both numerous and varied. We may, for example, require a characterization of logical and psychological attitudes in terms intelligible both to logic and to psychology; we may ask whether a single situation has a single meaning or whether it may have several meanings and, if so, how these meanings differ; we may inquire specifically into the conditions under which meaning occurs; we may investigate the temporal relation between a logical meaning and its correlated contentprocess ; we may seek evidence for or against the concept of brain-habit in other fields of systematic psychology, e. g., in recognition, memory, action; as physiological psychologists we may attempt an adequate account of brain-habit in physiological terms. Further problems will, no doubt, emerge as experiment proceeds.

II. The Experiment: 1. Problem. In planning our experiment we had two of the above mentioned problems in view. We hoped (1) to obtain characterizations of the logical and psychological attitudes, and (2) to make a preliminary investigation of the temporal relation between logical meaning and correlated content-process. As the work went on we found that our observers were responding to the experimental 
situation with several types of meaning. We therefore carried out further experiments, with change of method, in the hope of bringing these kinds of meaning into bolder relief.

2. Method, Apparatus and Observers. We employed a method of reaction; stimuli were presented to the observer, and reactions were taken separately to meanings and to visual imagery. The stimuli consisted of twenty-nine printed words, selected from ethnological and technical vocabularies, whose meanings were at the outset unknown to our observers.* We then furnished meanings by aid of pen-and-ink drawings of the objects represented by the words. The observers were instructed so far as possible to inhibit verbal and kinaesthetic learning. After a few repetitions of words and pictures, the learning was continued with words alone in the form of a practice series with reactions to the meanings; if a meaning could not be recalled, the picture representing the particular word was shown. As soon as the observer was able to go through the series without being shown a single picture, the experiment proper began. The stimuli were arranged in three groups of 9,10 and 10 , and the order of presentation of the groups was changed from series to series. ${ }^{4}$ The general instructions were as follows: "You will be shown a word: you are to react when you have grasped the meaning of the word, or when you have a visual image. Before the presentation of every word you will be told whether you are in its case to ' react to meaning' or to ' react to image."' In the first series the alternative instructions were given in irregular order, there being in all 15 instructions for image and $\mathbf{1 4}$ for meaning; in the second series the instruction for every stimulus was reversed; in the third, the order was the same as that of the first; in the fourth, it was again reversed,

${ }^{8}$ The stimuli arranged in groups as used in the experiments with D and $R$ were: (A) burin, peruke, brob, mino, parbuckle, costreL cresset, martlet, mace. (B) pavon, besague, chank, ampyx, mambrino, araba, chela, corbel, dagon, argali; (C) hippogriff, kago, hubblebubble, jougs, koto, heaume, sabbaton, aquaemanale, acontium, aplustre. The pictures employed were pen and ink drawings of the illustrations of the words as found in the Century Dictionary.

${ }^{4}$ There were originally 30 words, but one of these proved on trial to be vaguely familiar, and was accordingly discarded. 
and so on. Reports were not asked for during the regular series, although after a reaction to meaning the observers frequently volunteered a report of process. Series with report were, however, occasionally taken at the close of the regular series.

The apparatus consisted of a lip key, a tachistoscope, and a Hipp chronoscope. Before every experiment the chronoscope was tested by means of the large Wundt control hammer set at $150<\mathrm{r}$, and the strength of current was adjusted until the mean variation was equal to (or less than) $1.5<$ r. Previous tests of the same instrument had shown that when adjusted for constancy at 150a-, it was also reliable for intervals as large as $1750<r$. The observers were F. L. Dimmick (D), and J. G. Rich ( $R$ ), graduate students in psychology.

3. The Quantitative Results. The gross results for $D$ and $R$, consisting of the total reaction-times both to meaning and to image, together with the differences and the probable significance of these differences, are shown in Table $I$.

TABLE I

AVERAGE AND PROBABLE CORRECTNESS FOR TOTAL NUMBER OP CASES*

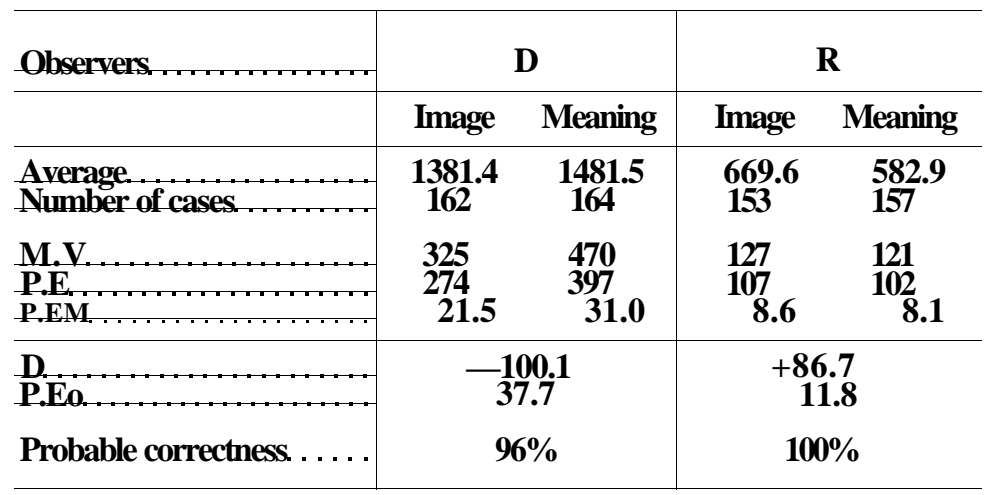

$D=$ difference between total times for meaning and total times for image. Plus = image-time is greater than meaning-time.

${ }^{\mathrm{B}}$ W. S. Foster, On the Perseverative Tendency. American Journal of Psychology, XXV., 1914, p. 408.

${ }^{6}$ For the method of determining probable correctness of the difference, see E. G. Boring, The Number of Observations upon which a Limen may be Based, American Journal of Psychology, XXVII, 1916, PP- 3i5ff. 
It will be noticed that $D$ gives reaction-times to meaning that are on the average longer than those to image, whereas $R$ gives reaction-times to meaning that are shorter than those to image. The probable correctness of the difference between the total averages is found to be $96 \%$ and $100 \%$ respectively.

Let us, however, turn to details. If we take the total reaction times of the series in order, as in Table II, facts

TABLE II

AVERAGE REACTION-TIMES BY SERIES

Observer D

\begin{tabular}{|c|c|c|c|c|c|}
\hline Series & Meaning & M.V. & Image & M.V. & Difference \\
\hline 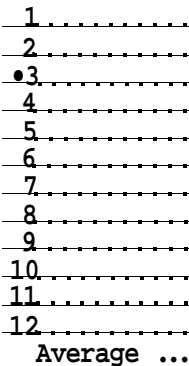 & $\begin{array}{l}1445 \\
1507 \\
2286 \\
1326 \\
2140 \\
1381 \\
1318 \\
1137 \\
1666 \\
1286 \\
1315 \\
1158 \\
1481.5\end{array}$ & $\begin{array}{r}285 \\
585 \\
713 \\
269 \\
1341 \\
205 \\
175 \\
175 \\
536 \\
232 \\
140 \\
75 \\
470\end{array}$ & $\begin{array}{l}1215 \\
1419 \\
1442 \\
2398 \\
1230 \\
1310 \\
1212 \\
1271 \\
1331 \\
1352 \\
1242 \\
1315 \\
1381.4\end{array}$ & $\begin{array}{r}116 \\
219 \\
357 \\
1353 \\
242 \\
156 \\
135 \\
211 \\
232 \\
299 \\
87 \\
193 \\
325\end{array}$ & $\begin{array}{l}-230 \\
-88 \\
-844 \\
+1072 \\
-910 \\
-71 \\
-107 \\
+134 \\
-335 \\
+66 \\
+133 \\
+100.1\end{array}$ \\
\hline
\end{tabular}

Observer R

\begin{tabular}{|c|c|c|}
\hline 1. & 736 & 92 \\
\hline 2. & 702 & 80 \\
\hline 3. & 642 & 62 \\
\hline 4. & 691 & 143 \\
\hline $5 \ldots \ldots \ldots$ & 593 & 76 \\
\hline $6 \ldots \ldots \ldots$ & 489 & 70 \\
\hline$\frac{7}{8} \ldots \ldots$ & 514 & 66 \\
\hline $\begin{array}{l}8 \\
0\end{array}$ & 391 & 33 \\
\hline $10 \ldots \ldots \ldots$ & $\begin{array}{l}641 \\
540\end{array}$ & 112 \\
\hline $11 \ldots \ldots \ldots \ldots$ & 469 & 81 \\
\hline Average $\ldots$ & 582.9 & 121 \\
\hline
\end{tabular}

\begin{tabular}{|c|c|c|}
\hline $\begin{array}{l}874 \\
798 \\
715 \\
720 \\
603 \\
575 \\
585 \\
526 \\
954 \\
589 \\
591 \\
669 .\end{array}$ & $\begin{array}{r}178 \\
175 \\
73 \\
110 \\
62 \\
66 \\
69 \\
69 \\
287 \\
94 \\
96 \\
127\end{array}$ & $\begin{array}{l}+138 \\
+96 \\
+73 \\
+29 \\
+9 \\
+86 \\
+71 \\
+135 \\
+313 \\
+49 \\
+122 \\
+86 .\end{array}$ \\
\hline
\end{tabular}

* Interval of three weeks.

which result from the serial nature of our experiment become apparent. For R, the image-times at first grow shorter and then tend to become constant; the average of the last six series (the 9th is disregarded since it occurred after an interval 
of three weeks) is $578 \pm 18.5$. The meaning-times tend to become shorter, but with less regularity; the average of the meaning-times of the same six series is $499 \pm 50$. For $D$, on the other hand, these relations are not obvious. There is, it is true, a slight tendency for the meaning-times to become progressively less, and for the image-times to grow constant; but in the odd-numbered series $3,5,7,9,11$, the meaningtimes are larger and the image-times are smaller than in the even numbered series $4,6,8,10$ and 12 . The reason is that four words, which were recalled with especial difficulty, happen to fall under the same instruction. For example, in the fourth series these words increased both the reaction-time and the $\mathrm{m}$. v. for image, and in the fifth they had a similar effect on meaning; in the sixth series two of them failed to call up images, and in the seventh two had no meaning. These effects cancelled each other in the total result, but they also tended to obliterate any tendencies of the kind which we observe in $\mathbf{R}$.

We turn next to the statements of our observers concerning the mental processes present when the meanings came. These results we give numerically in Table III.

We are fortunate in having so large a number of cases; the reports came and were recorded as a sort of by-product, and in so far are evidence of the skill of the observers. The record shows unmistakably that for $R$, at the outset, meanings came largely with visual context, and in the later series, were accompanied more and more frequently by verbal and kinaesthetic processes; for $D$, on the other hand, meanings almost invariably came visually. If now we compare the total reaction times of Table II with the reports of Table III, we note that $R$ in the second and fourth series and $D$ in the tenth and twelfth series gave meaning-times less than the image-times; yet, of the total of 57 meanings (both observers), 48 came with visual imagery. What is the explanation?

III. The Method and Results of Moore's Experiment. Before we attempt an explanation, we may compare these results with those obtained by Moore in an experiment undertaken as a test of the context-theory of meaning. ${ }^{7}$ Although, as we shall later see, Moore mis-

${ }^{\mathrm{T}} \mathrm{T}$. V. Moore, The Temporal Relations of Meaning and Imagery, Psychological Review, XXII, 1915, pp. 177-225. 
TABLE III

Observer R

\begin{tabular}{|c|c|c|c|c|c|}
\hline Series & Meanings & Visual & Verbal & Kinaes. & No report \\
\hline 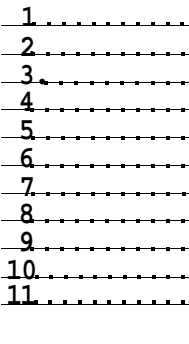 & $\begin{array}{r}14 \\
14 \\
14 \\
13 \\
15 \\
14 \\
15 \\
14 \\
15 \\
14 \\
15 \\
157\end{array}$ & $\begin{array}{r}\text { ii } \\
\text { io } \\
7 \\
7 \\
3 \\
3 \\
7 \\
4 \\
4 \\
56\end{array}$ & $\begin{array}{r}2 \\
3 \\
2 \\
5 \\
1 \\
5 \\
2 \\
22\end{array}$ & $\begin{array}{r}i \\
2 \\
i \\
3 \\
4 \\
3 \\
3 \\
7 \\
24\end{array}$ & $\begin{array}{r}14 \\
14 \\
1 \\
6 \\
3 \\
7 \\
2 \\
4 \\
2 \\
2 \\
55\end{array}$ \\
\hline
\end{tabular}

\begin{tabular}{|c|c|c|c|c|}
\hline \multicolumn{5}{|c|}{ Observer D } \\
\hline 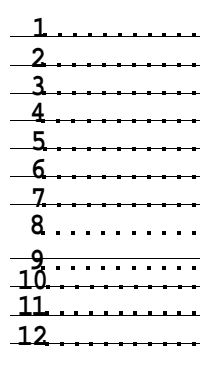 & $\begin{array}{r}12 \\
14 \\
13 \\
13 \\
13 \\
14 \\
12 \\
15 \\
14 \\
15 \\
14 \\
15 \\
164\end{array}$ & $\begin{array}{r}12 \\
6 \\
11 \\
2 \\
11 \\
13 \\
10 \\
10 \\
11 \\
14 \\
12 \\
13 \\
125\end{array}$ & $i$ & $\begin{array}{r}8 \\
2 \\
11 \\
\star \\
1 \\
2 \\
5 \\
3 \\
1 \\
2 \\
2 \\
37\end{array}$ \\
\hline
\end{tabular}

* 1 in word itself.

understood the theory in one important regard, and although he ignored the difference in attitude demanded by the theory, nevertheless he worked by a method of reaction; and the community of method allows us in a certain measure to check his results by our own, and thus $\wedge_{0}$ bring them into relation to the theory which he attacks. We proceed, therefore, to give a brief statement of Moore's method and results.

Moore used as stimuli the printed names of familiar objects such as tree, shears, key, fork, etc., and outline drawings of such familiar objects. These he presented one at a time to the observer, who in a typical experiment was instructed as follows: "Ich bitte Sie zu reagieren wenn Sie das Wort verstanden oder seine Bedeutung erfasst, bzw. wenn Sie eine Gesichtsvorstellung von dem durch das Wort bezeichneten Gegenstand gehabt haben." ${ }^{8}$ There were three groups of experiments. In the first words were shown, and reactions were made

- Op. cit., p. 189. 
separately to ' simple meanings' and to visual imagery. In the second words were shown, and reactions were made to meanings-of-purpose and to kinaesthetic imagery. In the third pictures were shown, and reactions were made to 'simple meanings' and to names. "If there is no difference between meaning and the visual image of an object represented by a word the average [reaction-times] of the two [paired] series should be approximately the same (within the limits of the experimental error) . . . . If meaning, however, is produced by or is identical with the visual image which accrues to the sensations involved in the perception of the word, the image series should be shorter if anything than the meaning series." showed, on the contrary, that the average reaction-times to meaning were almost invariably shorter than those to sensory processes; and he therefore decides against the context-theory of meaning. We are not concerned, however, at this point with Moore's conclusion; his results are here important simply as indicating a certain temporal relation between meaning and content-process.

Moore's observers, then, gave total reaction-times to meaning that were almost invariably shorter than those to imagery. Our observer, $R$, in the same way gives reaction times to meaning that are shorter than those to image; whereas $D$ gives reaction-times to meaning that are longer than those to image. The temporal relation of meaning to content-process appears, in the light of Moore's result, to be relatively simple; in the light of our own it seems complex. The difference between the two sets of results, if it were uniform, might perhaps be explained by the fact that Moore failed to employ the unfamiliar stimuli which are demanded by the context-theory for psychological contexts, and by the further fact that he failed to inquire whether the logical meanings and content-processes to which his observers reacted were, in fact, correlates. But it is not uniform. What, then, we must again ask, is the explanation?

IV. The Attitudes set up in our Observers by the Two Instructions. The explanation is to be found in the conditions of the experiment itself, and particularly in the different attitudes set up in the observer by the instructions. We have seen that Moore ignored this difference; whereas it was our purpose from the beginning to ask our observers, while under experimental conditions, to characterize the two attitudes. Hence, in the series with report we gave the following instruction: "You will be given a stimulus and an instruction to

- Op. cit., pp. i8Qi. We confess we are not clear as tc Moore's use of the term 'identical'; if it is taken literally neither of the two possibilities has any bearing upon the context-theory. 
react as in the regular series. After the reaction, however, we shall ask you to characterise as best you can the attitude under which you react. We do not want a psychological description of the mental processes which are present; we want rather a statement of what it is you are doing." The task is not easy, because the attitude is set up by the mere acceptance of the instruction; and the obvious reply, when one is asked what one is doing, is to restate the instruction. ${ }^{10}$ After repeated trials, however, we obtained fairly satisfactory results. The following are examples of the reports made.

D (Meaning). "When I saw the word I read it over a couple of times. A feeling of familiarity about it. I did not get the meaning until I got an image, a little curly-cue, not the complete picture, one curl of which seemed to be tacked on to the end of the stimulus word."

D (Image). "I read the word once, then an image of a spear-like thing shot out over the stimulus and blotted it out. Under this instruction I am looking for the image which the word calls up; under the meaning instruction I am looking for something which stands for the word, which fills it out. This something is usually an image . . . but the word and image go together."

D (Meaning). 'The instruction for meaning means for me something like 'Do you know what this means?' or, 'Do you know what this is?' The thing I report is not familiarity, and it is not a feeling that I know what it means; but I actually get or grasp the specific, concrete, particular meaning of the word .... When I am set for image I am set for the object rather than the pair word-andobject, as is the case under the meaning-instruction; in the former the word may drop out entirely; in the latter I must have both word and object, the word is important."

D (Image). "There seems to be less strain to the image instruction, it seems to have a more definite meaning, I know what an image is when I get it. I have a predetermination that I ought to get the meaning sooner (when under the meaning instruction), and I am on greater strain to report the meaning the instant it comes. I avoid the attitude that I shall get the meanmg when I get the image, because I think that would not be following instructions. In spite of the attitude to find meaning as quickly as possible, the image is always there; the difference between the two instructions is as I have reported before, word and image must, for some reason, be together."

$R$ (Meaning). "Under this instruction the intention is not set toward any particular sense department; it is indefinite; set for the cognitive value of the impression rather than the image. I hardly

${ }^{10}$ E. B. Titchener, Description vs. Statement of Meaning, American Journal of Psychology, XXIII., 1912, pp. 175. 
know whether I am justified in saying that 'attention' is set for the cognitive value; the whole disposition is toward it"

R (Image). "While waiting for the stimulus, expectancy that image will come. I feel that I must not react until the image comes. With the meaning instruction $I$ am set to react as soon as it means at all; in case of the image, I wait for the image."

$R$ (Meaning). "The characteristic of this instruction is that I am prepared to react as soon as I can. In the case of the image-instruction I feel that I must wait for the image. In this [the meaning] instruction I wait for the knowledge of what it means. I sometimes know the meaning before the image comes. This happened today when the stimulus was peruke; the verbal 'wig* came before the image."

$R$ (Image). "In this instruction I do not care whether I know what the word is, but whether I get an image of it; in the other instruction I do not care whether I get an image so long as I get the meaning .... The report of the image is easier than the report of meaning because it is more definite, it is easier to put my finger on."

These reports show that in the view of the observers there is a difference in the attitudes under the two instructions. The characterizations are general, however, and in our attempt to make them more specific we shall avail ourselves of other reports volunteered in the regular series or obtained in the regular report-series. We begin with the reactions to image.

I. Process-attitudes. In the early experiments the imagery was, as a rule, not complete at the outset. $R$ says: "Image kept on growing after the report"; "Spot of black changed to assume form of the object"; and D likewise reports: "Part of the imagery came first and then filled out"; "Left hand corner of the picture came first" For R, again, the images throughout continued to be 'hazy', 'not full of detail', 'scrappy'; they rarely reached full development, only once in later experiments did he report a 'detailed representation of the picture'; for $D$, on the other hand, the imagery was much more complete, it had a good deal of detail in parts and vague outlines in others; as the experiments progressed, the images became habitual, they seemed to appear-'all at once', and they did not change in detail. For D also some salient feature of the object, the feet of hippogriff, the spigot of aquaetnanole, the muzzle of argali, came to stand for the object as a whole; the whole, nevertheless, was always represented, even if vaguely. As regards the reactions of the two observers, $R$ was 'set to wait' for the image, and reacted at its onset. He was not set to assure himself that the image was of the correct object; it is true he often knew that his image was correct, since verbal and kinaesthetic meanings frequently came before the image; but he says specifically, the "intent is to notice it [the image] when it comes, as opposed to aware- 
ness of meaning", and again, ${ }^{\mathrm{M}} \mathrm{I}$ do not report when the image means but when it comes; ... the image is just the image, it is not reported as the image of something; this comes later." And there were a few instances in which he announced after the reaction that he had reacted to the wrong image. D, on the contrary, was set to report the image as image of something; the image always referred to some object, it 'was* that object He says: "I think both word and image stand for an object; the image is image-of, the word is name-of the object By this I mean that the image is not that of the picture, although it is like it; but the image is of the object, as if I had seen the object" This observer, therefore, did not react until the imagery had advanced further in its temporal course; he usually assured himself that the image 'was correct'; and he frequently rejected the first image that appeared because it was not correct

It is obvious that the two attitudes to react to image are not the same: $R$ was set by the instruction to report an image, regardless of the meaning of that image; $D$ was set to react to a particular meaning, which was, however, conditioned upon an imaginal process.

2. Meaning-attitudes. We pass to the meaning-attitudes. Both observers frequently stated that the reaction to meaning was the more difficult, because the determination was less definite; there was, as it were, nothing to which one could attend. Their reports show also that there were many meanings, not a single meaning, to which reaction might be made; the instruction, which required a reaction to 'the meaning/ proved therefore to be ambiguous, and as a result the observers did not react to the same thing. We begin with the reactions of $D$.

At the conclusion of the first preliminary experiment, D says : "Image and meaning now seem to come together. In peruke, mace, and cresset meaning seemed to come before image but in these cases the meaning was a 'feel', e.g., when the stimulus mace appeared I 'felf that I could describe it that I could call up the image, and this 'feel' was the meaning. Other stimuli, again, were familiar; I felt that I had seen them before. This was $a$ meaning, but I coufd not call up the meaning." $\mathrm{D}$, then, rejected the two 'felf meanings, and reacted to a meaning which In a later experiment he thus explains: "I am looking for something which stands for the word, which fills it out; this something is usually an image," and then, still later, he continues; "The image adds itself to the word, and the meaning seems to include the word." Thereafter, the meaning was for him specific; other meanings frequently came \{e.g., hippogriff "meant animal", costrel "meant that was the one that troubled me yesterday"; corbel meant "it was familiar"), but all these were rejected for what had become to him 'the meaning.' Finally, in the gth experiment, he says: "If I were to 
define meaning now I should say that it is the connection between the word and the image. Neither the word nor the image means in itself; they must be connected, one seems to 'point to- the other, to be directed toward the other. I do not mean that I am conscious of the pointing relation; it is only my way of expressing the thing. The two, word and image, are always together; when I try to hold the meaning I find my eyes shifting, as it were, from one to the other." This observer's predisposition and method are now apparent. He fixated the stimulusword; the image came and was localised on the exposure-card beside the word; when the word meant the object and the object meant the word, or when the meaning seemed to include both the word and the image of the object, he reacted,

For R, on the other hand, meaning was "knowledge about"; he was set for the "cognitive value of the impression." He found it difficult to be more explicit unless he turned to process. Thus, to the stimulus sabbaton he reported, "Hazy image of shoe, and this came in the sense of being the meaning of the word." When pressed for an explanation of 'in the sense of, he added: "Organics in the chest which seemed to mean 'this is the proper meaning/" In another instance he said: "My intent is to react as soon as I am aware of meaning regardless of process. I react to knowledge"; and when asked what it is to be aware of meaning, he replied: "Possibly a kinaesthetic feel that I do know; it is something like the feel of familiarity. In this particular case the word meant, however. I think the feel of knowing came with the meaning." He reacted, therefore, to the first bit of knowledge about the stimulus that came, and he did not trouble himself about the nature of his meanings. His reports show, nevertheless, that the range of his meanings was circumscribed; he did not, e.g., react as a rule to familiarity; and when (on two occasions) he did so he reported: "I reacted to familiarity, not to meaning." The range of meanings to which he did react can best be shown by examples. In the preliminaries every meaning came with visual imagery, and here the image was the object in exactly the same sense as in D's reaction under the image-instruction; "argali", R says, "is that image." But early in the regular series there began to appear kinaesthetic meanings. Thus, burin "came with kinaesthetic image of hand making a cutting motion," mace "kinaesthesis in arm as if hacking," and Verbal meanings also appeared: mino "coat"; koto "Japanese"; hippogriff "animal". These kinaesthetic and verbal meanings, as we have already seen, became more and more frequent, and the visual imagery more and more schematic, as the experiments progressed, until in the last three experiments there were instances in which the observer was unable to report at all how the meanings came. We do not forget that the observer reacted to meanings regardless of process, and our attempt to indicate the range of his meanings by reference to process is only a matter of convenience. 
We may now summarise the reports of attitude given by the two observers under the meaning-instruction. Both reacted to meaning. But $D$ reacted throughout to a specific meaning, namely the relation* between the stimulus-word and an imaged object, and $R$ reacted to a number of different meanings. Furthermore, both observers reacted to knowledge. But $D$ reacted to his own awareness of the meaning of the stimulus, $R$ to the cognitive value of the stimulus.

We go back to the quantitative results. It is obvious that, since our observers were reacting to different things, they could not be expected to give similar total reaction-times. $D$ under both instructions reacted to meaning; his total times under the meaning-instruction were longer than those under the image-instruction because the task he set for himself in the interpretation of the former, (that of relating the stimulus word to the imaged object) took more time than a reaction to the imaged object itself. $R$ according to instructions reacted both to image and to meaning; his total times under the image-instruction were longer than those under the meaning-instruction because under the former he was ' set to wait for the image,' whereas under the latter he was ' set to react as quickly as possible/ ' as soon as the stimulus meant at all/ The visual image was not in his case so habitual a process as were verbal and kinaesthetic images, a fact shown both by his waiting attitude under the image-instruction and by his early substitution of verbal and kinaesthetic meanings for the visual meaning. The quantitative data also point to this conclusion: we have seen that the image-times tended to become constant, whereas the meaning-times tended to become progressively smaller. Furthermore in the 9th experiment, which occurred after an interval of three weeks, there was an increase in the total meaning-times of more than 1000*, and there was also an increase in the number of meanings that came with visual imagery.

V. The Attitudes in Moore's Experiment. What, now, can we say of the attitudes in Moore's experiment? In the interpretation of his results Moore not only ignored (as we have seen) the difference in attitude demanded by the con-

* This type of meaning is discussed and explained below, p. 200. 
text-theory, but even when the possibility of a difference was subsequently pointed out to him, declined to entertain it. ${ }^{11}$ Fortunately we have his instructions and reports of his observers under the instructions; on this basis we may attempt an analysis of the general procedure of his observers.

The significant passage in the image-instruction reads: "Ich bitte Sie zu reagieren . . . wenn Sie eine Gesichtsvorstellung von dem durch das Wort bezeichneten Gegenstand gehabt haben." ${ }^{12}$ And Moore says: "The subject reacted to the awareness of the visual image of the object" The question is, of course: Did the observers react to the visual image as imaget Or-did they react to the image as the object designated by the stimulus word? The significance of the reaction-times depends, at least in part, upon the answer to this question. If the observers reacted to the image as image, then they reacted to psychological process; if they reacted to the image as object, then they reacted to a particular meaning of the stimulus-word. They seem, without any doubt, to have reacted to the image as object For (i) the instruction favors the setting up of the meaning-attitude rather than the image-attitude. The image-attitude has been clearly characterised by our observer $R$ : "The intent is to notice it [the image] when it comes, as opposed to awareness of meaning ... I do not report when the image means but when it comes; . . . the image is just image, it is not reported as the image of something; this comes later." Moore's instruction, however, calls for the image of the object. (2) Moore further weights the tendency to react to the object by asking his observers to characterise their experience after the reaction, "und dabei anzugeben, ob die aufgetauchte Vorstellung an die Stelle der Bedeutung gesetzt werden konnte, etwa bloss die konkrete anschauliche Erfullung dessen war, was in der Bedeutung abstrackt intendiert wurde."13 We question the possibility of following this instruction unless the image is regarded as object; the observers were set for a meaningful experience, and they were expected to compare meanings. (3) In the few reports which Moore quotes the images are given as objects and not as processes. "It [the image] looks like a large rocking chair"; "I imagined a part of a rake"; "Then there appears the color of the animal, I see 'brown'"; "The image did not

${ }^{11}$ Op. cit., p. 212.

12 Op. cit., p. 189.

${ }^{18} \mathrm{Op}$. cit., p. 189. The fact that Moore required this report of his observers indicates a misunderstanding of the context theory. In a later connection (p. 218) he says also: "It remains for Professor Titchener to prove that meaning is identical [italics mine] with the concomitant or subsequent imagery." On the contrary, the context theory has never stated that the content-process to which it appeals is even a representation of the logical meaning. 
really represent a radish but a turnip," "Then arose the head of an ox with his horns as drawn in the pictures of these experiments." ${ }^{14}$ A report of process, on the other hand, would have described the image as image, e.g. as hazy, scrappy, colorless, or the contrary, and as running a certain temporal course. Our observer $R$, it will be remembered, reacted at the onset of the image; he was not set to know whether the image was of the correct object; and after the reaction he occasionally declared that he had reacted to the 'wrong' image.

All these considerations point to the conclusion that Moore did not realize the difference between the image-of-object and the image as image; he did not see that the first is a particular meaning of the stimulus-word, whereas the latter designates a psychological process. If he had instructed his observers to react to a visual image, to the first visual image which came up, and had trusted to the situation to bring the correct psychological image, then he might have obtained reactions to content-process. But our own results have shown that the tendency toward 'objective reference' is so great, even in the case of experienced observers, that the instruction needs to be more explicit.

The same criticism holds, in principle, of Moore's other experiments. In the third, where he exposed pictures of familiar objects and asked his observers to react with the name, the chief concern was, apparently, to find a name which meant the stimulus, and not to react to a verbal-process. Only two reports from the word series are published $;^{1 \mathrm{~S}}$ in the one the observer says: "I knew that the meaning of the word was more general than that of the picture"; in the other, one word-meaning (Tulpc) was rejected for another (Glockenblume).

Finally, in the second experiment the observers were shown words with the following instruction: "Ich bitte Sie $\mathrm{zu}$ reagieren wenn Sie die Bedeutung des Wortes im Hinblick auf den Gebrauch oder die Funktion des damit bezeichneten Gegenstandes erfasst, bzw., wenn Sie eine kinaesthetische oder kinaesthetisch-optische Vorstellung davon gehabt haben."16 According to the seven reports of imagery which Moore quotes, the procedure of the observers was first to image the object visually, and then to represent the purpose of the object in visual-kinaesthetic imagery. In five of the seven cases the observers

${ }^{14}$ Op. tit., p. i07ff.

${ }^{15} \mathrm{Op}$. cit., p. $2 U$. Moore gives the second of these reports in the 'meaning* column; but reference to the table of reaction-times (Lehner, 209) shows that on the date indicated the reaction was, in fact, to the 'word.'

${ }^{16}$ Op. cit., p. 201. 
themselves report that the imagery did not completely fulfil the meaning of purpose. For example: Lampe "I imaged the lamp that I use in my dwelling, and saw clearly that it did not burn brightly enough, and then imaged the turning up of the wick. The kinaesthetic image of the movement cannot be identified with the consciousness of purpose."17 Trichter "Immediately after the simple meaning of the word, I had the visual image of a funnel and then the kinaesthetic image of laying hold of it with my right hand and placing it over an opening. Here also the kinaesthetic image falls short of being the fulfilment of the purpose. For I think that the funnel is the instrument by means of which I pour fluid through an opening, and my image is only the placing of the funnel in the opening." 18 The obvious inference from these cases is that the observers reacted to the visual-kinaesthetic-image, not as image, but as meaning.

In all three experiments processes,--visual imagery, verbalkinaesthesis, and visual-kinaesthesis,-were present; that we freely admit. Again, under all three instructions it is possible that the observers might have reacted to processes and not to particular meanings; that we also admit. But we have shown that Moore has failed to guarantee reactions to processes, that his instructions would tend to set up attitudes for meanings rather than for processes, and that the reports of the observers themselves indicate that they reacted, in fact, to meanings instead of processes.

VI. Various Types of Meaning to which our Observers Reacted. In the discussion of the attitudes of our own observers, we saw that they responded to the experimental situation with several types of meaning. When the experimental series of $D$ and $R$ were concluded, we thought it advisable to make a further study of these various meanings with a new observer. Accordingly we gave the same instruction that we had used with $D$ and $R$ to Dr. W. S. Foster (F), then instructor in psychology, who had had previous experience in meaningexperiments. $^{19}$ F demanded a further explication of the term 'the meaning' which occurred in the meaning-instruction. The only answer that seemed legitimate was to instruct him

${ }^{17}$ Op. cit., p. 207.

18 Op. cit., p. 207.

19 E. Jacobson, On Meaning and Understanding, American Journal of Psychology, XXII, 1911, p. 553; Titchener, Description vs. Statement of Meaning, Ibid, XXIII, 1912, pp. 1746*. 
further to react to the first meaning of which he was aware. The result was that he reacted to a number of types of meaning, most of which had already been reported in the earlier series by our other observers. We then changed the instruction so as to obtain reactions to particular types of meaning. The details of this new instruction, together with the quantitative results which we regard as indicative of the temporal relations of these meanings, we shall present in due course; for the present we propose to discuss in some detail the meanings themselves, and in so doing we shall avail ourselves of the statements of all three observers.

By way of preface three things should be said, (a) The list of meanings is purely provisional; it is the result of this experiment only, and future work will doubtless show the need of restatement, (b) We have tried to limit ourselves absolutely to the meanings of which the observer was aware at the moment of reaction. The observer may, in the explication of a meaning, state a new meaning, that was not present at the moment in which the reaction occurred. ${ }^{20}$ The experimenter must always be on guard against such intruders, (c) The order in which we discuss the meanings is insignificant.

(1) The stimulus-object is familiar. The familiarity was verbally explicated by some such phrase as, "I have seen it before," "I had that word yesterday." 21 Occasionally the meaning is more specific, e. g., "That is the word that gave me trouble yesterday." This meaning was consciously rejected by $D$ on the ground that it was not ' the meaning;' it was not considered as a possible meaning by $R$; and it was frankly accepted as ' the meaning' by $F$. Psychologically, the context was a diffuse sense-feeling, the 'feeling of familiarity,' a 'glow.'

(2) The stimulus-object is known. The observer is aware that the stimulus has a meaning which he could work out in definite form. F's usual statement was: "I'm all right to get the meaning." This meaning was, again, rejected by

${ }^{20}$ Cf. G. E. Muller, Zur Analyse der Gedachtnistatigkeit und des Vorstellungsverlaufes, I. 1911, pp. 65L, I37ff.; E. B. Titchener, The Schema of Introspection, American Journal of Psychology, XXIII, 1912, p. 503.

${ }^{81}$ This type of meaning is reported also by A. Binet, L'Hude explrimentale de t'intelligence, 1903, p. 74. 
$D$; it was probably the basis of some of R's reactions; and it occurred frequently in the case of F." Psychologically it was said to be carried by a "feeling that I know," " a kinesthetic feel, something like familiarity," a feeling of " relaxation" localised principally in the eye-muscles. F reported cases in which the feeling of familiarity or the ' glow' fused with this relaxation, and he also reported meanings that were partly familiarity and partly " I'm all right."

(3) The stimulus-object is something which arouses this sort of feel. The nature of these meanings, which were reported frequently by $F$ and occasionally by $R$, can best be shown by examples. F says: poulaine "I reacted to the attitude I have for men wearing tights and pointed slippers;" quern " Means attitude for something Irish and old;" pschent "I reacted to the conscious attitude that stands for ancient Egypt;" brob " Means the feel I get for a blunted-at-each-end thing, a feeling which, if explicated, is horizontal and blunted at both ends; the real brob is wedge-like;" kylix " A kinesthetic set which means it is that kind of a thing." $R$ similarly states: dagon "A kinaesthetic feel as if back were arched." 28 Psychologically, these meanings correspond with conscious attitudes which for the most part remain unanalysed; in the last two cases mentioned above, a kinaesthetic component was clear enough to be reported. Finally, the meanings of this type may precede, may follow, and may accompany the form of meaning given under (2).

(4) The stimulus-object is this kind of movement. It, is a movement which, regarded as an expressive movement or gesture, is ay if something were predicated of the object. For example, mace meant a movement as if to strike; burin as if to cut; jougs as if to encircle. For $F$ such a meaning occa-

${ }^{22}$ Meanings of this type are also reported by H. J. Watt, Experimentelle Beitrage zu einer Theorie des Denkens, Archiv fur die gesamte Psychologie, IV, 1905, pp. 317ft; A. Messer, ExperimenteU-psychologische Untersuchungen fiber das Denken, $i b$., VII, 1906, pp. 71, 77; J. R. Angell, Thought and Imagery, Philosophical Review, VI. 1897, 648. They are described by G. F. Stout in his summary of 'implicit apprehension/ in Analytic Psychology, 1909,1, 95.

"Messer, op. cit., pp. 77-80, includes this type under the term Spharenbewusstsein. 
sionally followed a meaning of the preceding type and rendered it more definite; $e$. g. $f$ skean was at first a feel of a long lean thing, then a movement as if striking something. It is important to note that the two observers who report these meanings insist that the meaning is the movement, or as F put it: "Besague is this" and he makes a movement as if cutting something. Furthermore, both observers think that the nearest approach to the meaning in spoken language is a verb; e. g., mace means strike, burin cut, brob drive, etc.; the two former do not mean objects with which one strikes or cuts, and the latter does not mean an object which one drives (as a nail).

(5) The stimulus-object is that object. In these cases the object was always present in visual imagery, but at the moment of reaction the image was as truly the object as if this were given in perception. ${ }^{84}$ It is characteristic of all our observers that some salient feature of the object comes, in the later experiments, to carry the meaning. For $D$ the object as a whole was also represented in imagery, even if vaguely, whereas for $R$ and $F$ the salient feature ultimately stood alone. In such cases there was no conscious reference from the salient feature to the object as a whole; and in one instance, after the experiment had come to a close, the observer was unable on reflection to say more about the object than that "It was something that had a spigot." (The stimulus was aquaemanale.) There were cases, however, when upon reflection the observer knew well enough that the visual object to which he reacted was not the -object which belonged to the stimulus-word; $e$. g., $\mathrm{R}$ said on one occasion, after reacting to the meaning of aplustre, "If you were to show me the image I had and ask me to name it I should not say ' aplustre.""

"In the early series when the meaning of the stimulus was as a rule the imaged object, $F$ frequently reacted to the meaning "I'm all right to get the image" (a type that belongs to group 2). In the later series this meaning was well known also to $R$, who thinks it possible that in the early series he often reacted to it instead of to the imaged object itself. This, we think, is the probable explanation of those series of $R$ (see p. 186) in which the meaning-time was less than the image-time, while yet the meaning was reported as 'image/ 
(6) The stimulus-object is this name. The meaning of this type most nearly approaches the definitional meaning of logic. The general form is a definition of the stimulus in intension; e. g., argali goat; peruke wig; mino coat; hippogriff animal, etc. In some cases, however, the meaning is in extension; koto, for example, is a Japanese musical instrument, and $\mathbf{R}$ reacted to this stimulus with the word ' Japanese."' We believe that usually if not always the name was first applied to the object when pictured or imaged. In our attempt to force a visual learning of our stimuli, we required our observers to inhibit a verbal response; yet in the first experiment $R$ reacted to peruke with 'wig/ In the later experiments $\mathrm{R}$ reacted to pavon with the word ' spear;' pavon, however, is not a spear, but a pennon fastened to the shaft of a mediaeval lance; the lance became the salient feature, and was visualised without the pennon, as the object; finally, when the object dropped away and the word took its place, ' spear' was the meaning of pavon.

(7) To these six we may, from the reports of $D$, add as a last type of meaning: The stimulus-word is related to the stimulus-object. It will be recalled that $\mathrm{D}$ reacted when the stimulus-word and the imaged object were in the same visual field. His report runs: "It [meaning] is the connection between the word and the image. Neither the word nor the image means in itself; they must be connected; one seems to ' point to' the other, to be directed toward the other. I do not mean that $I$ am conscious of the pointing relation; it is only my way of expressing the thing." D later remarked that, when he accepted the instructions, he interpreted the term 'meaning' in the sense of something that the stimulus-word 'stands for* or 'points to/ In the earlier experiments this ' something' was always the imaged object, and so, the spatial contiguity of stimulus-word and imaged-object came eventually to touch off the meaning-response.

Here, then, are seven 'types' of meaning, logically distinguishable. No doubt there are still other types which further experiments might have revealed; no doubt also other

${ }^{35}$ For similar meanings of this type see Messer, op. cit., p. $8 \mathrm{i}$. 
interpretations of a general instruction to ' react to meaning' may be made under other experimental conditions."

VII. The Types of Meaning to which Moore's Observers Reacted. It will be instructive at this point again to examine Moore's paper with a view to the interpretation which his observers put upon the meaning-instruction, and the nature of the meanings to which they reacted.

As we have already seen, Moore performed three groups of experiments; the first and third had an instruction which was practically the same as our own; his stimuli, however, were familiar words, whereas ours were unfamiliar. The significant phrase of Moore's instruction reads: "Ich bitte Sie zu reagieren wenn Sie das Wort verstanden oder seine Bedeutung erfasst haben." ${ }^{2 T}$ The obvious sense of this instruction is that the observers were to react when they understood the word or grasped its meaning. But Moore himself says: "In this series, therefore, the subject reacted .... to the awareness that the word had a meaning." Now it is one thing to understand a word, or to grasp its meaning, and quite another thing to be aware that the word has a meaning. What, then, did Moore's observers really do? We are not told; but we'find that, of the fifteen statements of meaning which Moore quotes, only four (two by Moore, one by Kulpe, and one by Marezoll) conform to Moore's own interpretation of his instruction.. These meanings fall under our own second type. For example, Marezoll says: "I knew that the word was something with which I was familiar, and knew that from this point I could get the meaning." 28 Moore makes a similar statement: "At first a feeling of familiarity was present and then a feeling of certainty that $I$ knew what the word [shears] signifies without analysing its meaning further. First during the reaction itself there came the further thought 'something with which one cuts'." $2 *$ Kulpe likewise reports: "Immediately after I saw the picture [of a horse] I experienced a tone of familiarity and knew what this picture represented .... The tone of familiarity was related not to the picture but to what it signified. The picture was a symbol of real objects and its signification consisted herein, vis., to point to them." «•

Of the eleven remaining statements of meaning quoted by Moore, six

${ }^{28}$ Both Binet, op. cit., pp. 73f, and Messer, op. cit., pp. >3ff, 75 (4), report cases in which the stimulus-word had no meaning other than as bare word; and Messer in this connection also reports the meaning of strangeness.

${ }^{2 \mathrm{~T}}$ Op. cit., p. 189.

${ }^{28}$ Op. cit., pp. 197, 208. We refer to the first of the two meanings here reported.

${ }^{28}$ Op. cit., p. 197.

${ }^{80}$ Op. cit., p. 211. 
give meanings-of-purpose, four imply general concepts, and one apparently corresponds with our sixth type, i. $e$., is a name. ${ }^{81}$ All but one of the meanings-of-purpose were obtained under a special determination to react to meanings of this kind; the exception is a reply of Kulpe's to Dampfschiff: "A means of transport by water."" Two of die others were purposive concepts of a class of objects and were also cast in verbal form: e.g., eye-glasses means "The correction of an error of refraction," and clock "Tells the time of day;" the rest were of particular objects, and in every case the particular object was also visualized: e.g., chain "I pictured to myself a tolerably strong chain and remembered ... that such chains are used to tie animals in their stalls;" fork (Gabel) "An instrument for eating, accompanied by a weak visual image of a fork." It might be mentioned in passing that if the stimulus, in these cases, had brought up a different kind of visual, object, then the meaning of purpose would have been different; Gabel, for instance, might have brought visual imagery of the frog of a horse's foot, which has a purpose different from that of table forks.

One of Moore's meanings which we have classed as a general concept may be a visual object. To the stimulus Geier, Marezoll gives the meaning: "I knew that it was something that hovers over mountains in the air-even though I did not see the mountains. Visually I imaged only a pair of extended wings and knew that something belonged between them." ${ }^{88}$ The others are undoubtedly general concepts; all are given by Kiilpe. ${ }^{8 *}$ Examples are: Kerze "There came to me at once the word Might' This was not a determination of the meaning, but only another word for it. The meaning was entirely general, as if I should say a candle, that is, any candle-every possible candle;" VeUchen "Immediately after the word appeared I had an auditory-kinaesthetic image of it as I pronounced it, VeUchen, and in connection therewith a general knowledge of its meaning that $I$ can thus explain: a definite species of flower. I dare say that it is this which makes up the content of the meaning-what I actually knew about this object during the experiment

The net result of our examination of that part of Moore's paper which deals with meanings is (1) that his observers interpreted differently the meaning-instruction, and (2) that the only types of meaning which differed from those found in our experiment are meanings-of-purpose and general concepts. It is worthy of note that all of the latter kind were

${ }^{81}$ Op. cit., (Lehner) p. 211; see footnote 15 of this paper, p. 195.

82 Op. cit., (Kiilpe) p. 198; (Lehner) pp. 206, 207; (Kiilpe) pp. 206, 207; (Moore; second meaning) p. 208.

${ }^{88}$ Op. cit., p. 198.

${ }^{84}$ Op. cit., pp. 197 (two meanings), 198. 
furnished, under the general instruction to react to 'the meaning/ by Kulpe, who was epistemologist as well as psychologist; and that all but one of the meanings-of-purpose were obtained under the express instruction to react to such meanings.

VIII. The Temporal Relation of Different Types of Meaning. We now return to the quantitative results obtained from F. Before we began these experiments we had noticed that the reactions of Moore's O's to meanings-of-purpose were twice as long as those to simple meanings, and that D's reactions to ' imaged objects' were almost invariably shorter than those to his ' relational meanings;' we had also found that the average time of Names reported by $R$ in the last four series was $499 \pm 109$, whereas that of Objects was $572 \pm 119$ (the probable correctness of the difference of these two averages is $93 \%$ ). Since $\mathbf{F}$ in the preliminary series had reacted to meanings of various kinds we hoped through him to get some knowledge of their quantitative relations. It will be recalled that $F$ began with the same instruction as $D$ and $R$. In Table IV we give the separate times of all the meanings of the three series in which $F$ reacted under this instruction, t. e., to the first meaning of which he was aware, and also (in the last column) the averages of his times under the ' image-instruction/

The Table shows, first of all, clean-cut differences of average within the series. We have averaged only those times, under a given heading, of which there were at least three cases; and in no instance is the probable correctness of the difference between averages less than $99 \%$. The * image '-times, though obtained under the image-instruction, represent reactions to the imaged object (not to the psychological image). They should, therefore, be approximately the same as the average Objecttimes obtained under the meaning-instruction. That this is the case is shown, at the foot of the table, by the probable correctnesses of the differences.

A second noteworthy feature of the table is the decrease of average in successive series. The times of Objects (and 'images') decrease in magnitude progressively throughout the experiment. Other meanings, whose times at all stages 
TABLE IV

REACTION TIMES OF F TO VARIOUS TYPES OP MEANING IN SERIES 1,2, AND 3 (GENERAL INSTRUCTION)

\begin{tabular}{|c|c|c|c|c|c|c|c|}
\hline Series & Fam. & $\underset{\text { right }}{\text { All- }}$ & Feel. & Obj't. & Name & $\begin{array}{c}\text { Unde- } \\
\text { ter- } \\
\text { mined }\end{array}$ & Image \\
\hline \multirow{3}{*}{1} & & $\begin{array}{l}595 \\
624 \\
652\end{array}$ & & \multirow{2}{*}{$\begin{array}{l}2849 \\
1106 \\
1036 \\
1202 \\
1035 \\
1029 \\
1467\end{array}$} & \multirow[t]{3}{*}{1677} & \multirow{3}{*}{$\begin{array}{r}746 \\
798 \\
1160 \\
707\end{array}$} & \multirow[t]{3}{*}{$\begin{array}{c}\text { Average of } \\
13 \text { cases } \\
1342 \pm 707\end{array}$} \\
\hline & & \multirow[t]{2}{*}{$624 \pm 19$} & & & & & \\
\hline & & & & $\begin{array}{r}1403 \\
\pm 460\end{array}$ & & & \\
\hline \multirow[t]{3}{*}{2} & \multirow[t]{3}{*}{ (515) } & \multirow[t]{2}{*}{$\begin{array}{l}465 \\
578 \\
505 \\
513\end{array}$} & \multirow[t]{2}{*}{$\begin{array}{l}655 \\
706 \\
565 \\
639\end{array}$} & $\begin{array}{r}1376 \\
1773 \\
735\end{array}$ & \multirow[t]{3}{*}{756} & & \multirow[t]{3}{*}{$\begin{array}{c}\text { Average of } \\
14 \text { cases } \\
1024 \pm 518\end{array}$} \\
\hline & & & & \multirow{2}{*}{$\begin{array}{r}1293 \\
\pm 374\end{array}$} & & & \\
\hline & & $515 \pm 31$ & $641 \pm 37$ & & & & \\
\hline \multirow[t]{2}{*}{3} & \multirow{2}{*}{$\begin{array}{l}(\mathbf{5 6 6}) \\
(\mathbf{5 0 2}) \\
\\
\mathbf{6 7 7} \\
\mathbf{6 5 6}\end{array}$} & $\begin{array}{l}698 \\
529 \\
663 \\
663\end{array}$ & \multirow[t]{2}{*}{$\begin{array}{l}608 \\
604\end{array}$} & $\begin{array}{l}880 \\
668 \\
991\end{array}$ & & & \multirow[t]{2}{*}{$\begin{array}{c}\text { Average of } \\
14 \text { cases } \\
784 \pm 138\end{array}$} \\
\hline & & $629 \pm 68$ & & $\begin{array}{c}846 \pm 119 \\
(2668) \\
(2658)\end{array}$ & & & \\
\hline
\end{tabular}

Series 1-Av. Obj't-Av. Image (1403-1342) 61. Prob. Cor. of Difference $57 \%$.

Series 2-Av. Obj't-Av. Image (1293-1024) 269. Prob. Cor. of Difference $76.5 \%$.

- Series 3-Áv. Obj't-Av. Image (846-784) 62. Prob. Cor. of Difference $75 \%$.

The cases in parentheses are half Familiarity and half All-right. Those in brackets are delayed meanings.*

are less than those of Objects, increase in number in the later series. As the work proceeds, under the general instruction, Object gives place to Feel, All-right, and Familiarity; meanings of a concrete and imaginal kind to those of a vaguer and ' attitudinal' sort. Both results may presumably be attributed

so No adequate meaning came at once and the observer sought the visual image. In the one of these a Familiarity and in the other a Feel came just before the reaction to the Object. 
to practice; but practice works in the one case by simple decrease of time within a given category, and in the other case by change of recourse from the more to the less time-taking mode of reaction.

IX. The Temporal Relation of Meaning and Correlated Process. In discussing the types of meaning (pp. ioj6ff) we made mention of their correlated processes. For example, $\mathrm{F}$ reported a sense-feeling, a ' glow/ as* the correlate of $\mathrm{Fa}$ miliarity, and a 'relaxation/ localised principally in the eyemuscles, as that of All-right. It is obvious that, if the attempt is made to investigate by the reaction-method the temporal relation of meanings and processes, Familiarity must be paired with ' glow/ All-right with ' relaxation/ and so on. We accordingly formulated a series of six instructions, as follows:

(i) You arc to react to meaning: If Familarity conies react to it.

(2) You are to react to meaning: If All-right comes react to it.

(3) You are to react to meaning: React when you have grasped the meaning.

(4) You are to react to process: If ' glow' comes, react to it.

(5) You are to react to process: If ' relaxation' comes, react to it.

(6) You are to react to process: If visual image, kinaesthesis, etc., comes, react to it.

The average reaction-times and the probable correctness of their differences, obtained in Series 4-7 (in which the above instruction in whole or in part was employed), are shown in Table V.

Looking first at the meanings, we see that the average times of Familiarity in Series 4 are shorter than All-right; the probable correctness of the difference is $94.5 \%$. The average times of All-right in Series 6, however, show that these meanings may with practice and under a single determination become as ready as Familiarity. The average reaction-times of the correlated processes tell a similar story. The average time of 'glow' in Series 4 is less than that of ' relaxation / the probable correctness of the difference is $99.7 \%$. In Series 7 , though 'glow' is again less than 'relaxation/ the probable correctness of the difference is only $72 \%$. The times of All-right in Series 4 are shorter than those of 'Meaning is grasped/ whereas 'relaxation* is longer than image, kinaesthesis, etc. We return to this variation later. 


\section{TABLE V}

AVERAGE REACTION-TIMES OP F TO VARIOUS TYPES OP MEANING AND TO CORRELATED CONTENT-PROCESSES IN SERIES 4, 5, 6 AND 7 (SPECIAL INSTRUCTION).

\begin{tabular}{|c|c|c|c|c|}
\hline \multirow{2}{*}{ Series } & \multicolumn{2}{|r|}{ Meaning } & \multicolumn{2}{|r|}{ Content-processes } \\
\hline & $\begin{array}{c}\text { No. } \\
\text { of } \\
\text { cases }\end{array}$ & Type & $\begin{array}{c}\text { No. } \\
\text { of } \\
\text { cases }\end{array}$ & Type \\
\hline 4 & $\begin{array}{r}10 \\
10 \\
9\end{array}$ & $\begin{array}{l}\text { Familiarity } 540 \pm 37.5 \\
\text { "All-right* } 602 \pm 94 \\
\text { Meaning } 726 \pm 106\end{array}$ & $\begin{array}{l}10 \\
10 \\
10\end{array}$ & $\begin{array}{lc}\text { "Glow" } & 559 \pm 42 \\
\text { "Relaxation" } & 684 \pm 102 \\
\text { Image, kin., etc., } 617 \pm 82\end{array}$ \\
\hline 5 & 10 & "All-right" $617 \pm 42$ & & \\
\hline 6 & $\begin{array}{r}11 \\
9 \\
5 \\
3 \\
1\end{array}$ & $\begin{array}{lr}\text { Familiarity } & 531 \\
\text { "All-right" } & \mathbf{5 3 4} \\
\text { Fam. All-R. } & \mathbf{5 1 7} \pm \mathbf{4 2} \\
\text { Feel. } 531 & \mathbf{4 5 5} \\
\text { Unidentified } & \mathbf{1 0 0 1}\end{array}$ & & - \\
\hline 7 & & & $\begin{array}{l}10 \\
10\end{array}$ & $\begin{array}{lr}\text { "Glow" } & 494 \pm 54 \\
\text { "Relaxation" } & 511 \quad \pm 59\end{array}$ \\
\hline
\end{tabular}

Probable correctness of the difference (Series 14) between:

Familiarity and All-right $\ldots \ldots \ldots \ldots \ldots \ldots \ldots \ldots \ldots+5 \%$ M. is grasped and All-right $\ldots \ldots \ldots \ldots \ldots \ldots \ldots \ldots \ldots \ldots+9.2 \%$ Relaxation and Glow. . . . . . . . . . . . . . . . . " Image, etc. and Relaxation $\ldots \ldots \ldots \ldots \ldots \ldots \ldots \ldots, \mathbf{9 0 . 0 \%}$ Familiarity and Glow $\ldots \ldots \ldots \ldots \ldots \ldots \ldots \ldots, \mathbf{8 0 . 0 \%}$ All-right and Relaxation $\ldots \ldots \ldots \ldots \ldots \ldots \ldots \ldots .93 .3 \%$ M. is grasped and Image, etc. . . . . . . . . . . . . .

What conclusion, now, may we draw as regards the temporal relation of meaning and process? The reader may think that the number of cases is insufficient to any conclusion. We shall, however, venture upon a discussion.

It will be recalled that Moore assumed the adequacy of the reaction-method to determine the temporal relation of meaning and correlated process. Thus far we have not questioned this assumption; we have been content to set forth the conditions which must be known and brought under control before the two sets of times may properly be compared. We now, however, suggest the possibility that a difference between the averages might be due, not to the temporal relation of meaning and process, but to the time required for 
reaction itself. Just as reactions to sound are shorter than those to smell, reactions to tonal intensity shorter than those to quality, reactions to minor shorter than those to major chords, so it might be that reactions to meaning are shorter than those to process. The organism is indubitably more accustomed to react under the meaning instruction or in the meaning attitude. The first two lines of the Table seem, in fact, to bear out this hypothesis; for Familiarity is somewhat shorter than 'glow/ and All-right than ' relaxation/

There is, however, a second possibility. Meaning-time and process-time may be identical within the limits of variation of the reaction course. In support of this hypothesis, the Table shows, as we have seen, that the temporal relations of Familiarity and All-right are paralleled by those of ' glow' and 'relaxation* (Familiarity in Series 4 is shorter than All-right, ' glow' than ' relaxation/ All-right shows the effect of practice more than Familiarity, and ' relaxation' than 'glow')- Furthermore, the relative m. v/s in Series 4 are almost exactly the same for Familiarity as for ' glow/ and for All-right as for 'relaxation/ The third line of the Table may also be interpreted in favor of the hypothesis. The meanings were, for the most part, Objects and Names; the correlated processes were visual images and kinaesthesis. We have here, on the one hand, a complex of processes which may touch off a reaction at an early stage of its course, and on the other hand a meaning which can emerge only when the complex has taken on a fairly definite form. ${ }^{86}$

In view of the complexity of the subject any more definite outcome could hardly have been expected. The results seem to warrant a further investigation in which after a certain type of meaning and its process-correlate have emerged, very definite instructions shall be given to the observer and a long series of paired reactions taken. Even so there is, of course, no guarantee that the effect of practice upon the two series will be the same.

X. Summary. This investigation was undertaken as the study of a part-problem within the context-theory of meaning. While it has shown that the subject is far more complex » Sec R's report pp. igof. 
than existing formulations of that theory, or previous experimental work, had indicated, it has, nevertheless, revealed nothing out of accordance with the theory. Special results may be summarised as follows.

(1) The meaning-attitude is that of establishing the signification or reference of a stimulus-object. The process-attitude, on the other hand, is that of reporting or describing psychological experience without reference beyond itself.

(2) The meanings which emerge are individual or prelogical meanings. Under a general instruction to react to 'the meaning* various types of meaning appear, which are logically distinguishable and which, within the limitations of practice, have different average reaction-times.

(3) The method of reaction thus promises to be useful in this sort of inquiry; with certain experimental safeguards, it appears adequate to a distinction of types of meaning and, combined with statements of meaning and with introspection, it promises to throw light on the temporal relation of meaning and correlated-process.

(4) An incidental analysis of Moore's method and results shows that the conclusion which he has drawn, adversely to the context-theory of meaning, is not substantiated. ${ }^{87}$

${ }^{87}$ See also an article which has appeared since this paper was written; E. C. Tolman, More Concerning the Temporal Relation of Meaning and Imagery, Psychological Review, XXIV, 1917, pp. 114-138. 